\title{
Changes in Opioid Utilization Following Tumor Necrosis Factor Inhibitor Initiation in Patients with Rheumatoid Arthritis
}

\author{
Siyeon Park (D) - Tham T. Le · Julia F. Slejko • Ester Villalonga-Olives • \\ Eberechukwu Onukwugha
}

Received: August 29, 2019 / Published online: October 18, 2019

(C) The Author(s) 2019

\section{ABSTRACT}

Introduction: Pain control is one of the most important aspects of rheumatoid arthritis (RA) management from the patient's perspective. Newer generations of RA treatment including tumor necrosis factor inhibitor (TNFi) have the potential to alleviate pain and thus reduce opioid utilization. However, patterns of opioid utilization before and after TNFi initiation have not been well characterized. This study aims to examine multiple measures of change in opioid utilization after the initiation of TNFi.

Methods: Patients aged $\geq 18$ years with RA and 24 months continuous enrollment between January 2007 and December 2015 who newly initiated a TNFi in IQVIA ${ }^{\mathrm{TM}}$ Health Plan Claims Data were included in our study. Opioid utilization at baseline and during follow-up were identified and compared.

Results: Of 2330 patients with RA that were included in the study, $38.8 \%$ of patients used opioids in both baseline and follow-up periods.

Enhanced Digital Features To view enhanced digital features for this article go to: https://doi.org/10.6084/ m9.figshare.9907310.

S. Park $(\bowtie) \cdot$ T. T. Le · J. F. Slejko

E. Villalonga-Olives · E. Onukwugha

Department of Pharmaceutical Health Services

Research, University of Maryland School of

Pharmacy, Baltimore, USA

e-mail: siyeon.park@rx.umaryland.edu
From pre-index to post-index, the proportion of patients receiving any opioid decreased from 54.0 to $51.0 \%$. In addition, the proportion of those who received $\geq 50 \mathrm{mg}$ median daily MED decreased from 12.6 to $10.6 \%$ during pre-post periods.

Conclusions: This real-world study of commercially insured patients with RA suggests that opioid use among these patients is prevalent. There was a small decrease in overall opioid utilization after TNFi initiation.

Keywords: Biologic treatment; Claims database; Opioid; Rheumatoid arthritis; Tumor necrosis factor inhibitors

\section{INTRODUCTION}

Rheumatoid arthritis (RA) is a progressive inflammatory immune-mediated disorder [1]. In the United States, approximately 1.36 million adults, comprising $0.6 \%$ of the population, are affected by RA [2]. Fatigue, joint inflammation, pain, and deformities are key complications of RA leading to impaired physical functioning, work productivity, activities of daily living, and compromised overall emotional well-being [3]. Medications currently recommended for the management of RA in the United States include corticosteroids, conventional disease-modifying antirheumatic drugs (DMARDs), targeted DMARDs, and biologic 
DMARDs [4, 5]. Historically, treatment of RA focused on symptom control and pain management. However, the development of new DMARDs including tumor necrosis factor inhibitor (TNFi), which slow clinical and radiographic progression of RA, has changed the paradigm of disease management by making disease remission the treatment goal [5]. Besides achieving remission or low disease activity, control over symptoms such as pain is of primary importance to many patients with RA [6]. Pain is often included in assessment tools for measuring disease activity [7]. However, pain control is an unmet need among RA patients and many patients continue to experience unacceptable levels of pain despite treatment for pain [8].

Understanding about opioid utilization in the RA population is critical for stakeholders who are involved in disease management of this population. It is estimated that about $40-55 \%$ of RA patients utilize opioid analgesics $[9,10]$. Despite its widespread use, the role of opioids in pain management of RA is not well established in clinical guidelines. In a Cochrane review by Whittle et al., the authors concluded that common adverse events may offset the benefits of oral opioids [11]. Further, use of opioids in RA patients might suggest uncontrolled pain or be indicative of an unmet need in pain control of this population. Finally, there are well-documented risks associated with opioid use including overdose and opioid use disorder [12]. In studies specific to the RA population, use of opioids increases risks of infection and fracture $[13,14]$.

For these reasons, the treatment strategy to reduce opioid use in RA patients is of interest. Newer generations of RA treatments including TNFi have a potential to reduce use of other medications for pain control including opioids. Previous studies have found TNFi agents may have an opioid-sparing effect in patients with RA $[15,16]$. However, understanding of patterns of opioid use in RA patients with TNFi initiation is still limited. The purpose of this analysis was to assess opioid utilization before and after TNFi initiation in a commercially insured population with RA.

\section{METHODS}

\section{Data Source and Patient Selection}

This retrospective cohort study used a 10\% random sample of enrollees within the IQVIA ${ }^{\mathrm{TM}}$ Health Plan Claims Data between January 1, 2007 and December 31, 2015. The database includes fully adjudicated medical and pharmacy claims from health plans and self-insured employer groups for over 10 million beneficiaries in the United States. The patient identification period is from January 1, 2008 to December 31, 2014. The index date was the date of the first TNFi claim during the patient identification period. TNFi utilization was identified by national drug code or healthcare common procedure coding system codes for etanercept, adalimumab, infliximab, certolizumab, or golimumab. Opioid utilization measures were identified during the 12-month period before (baseline period) and the 12-month period after (follow-up period) TNFi initiation.

Patients eligible for our study had two claims of RA [International Classification of Diseases, Ninth Revision, Clinical Modification (ICD-9CM) code 714.x except 714.3 and 714.9] 60 days apart with at least one claim in the baseline period. Study individuals were required to have 12 months of continuous enrollment in the health plan before and after the index date (total enrollment of 24 months). Patients were excluded if: (1) their age at index date was less than 19 years, (2) they had claims for any biologic DMARD therapy in the baseline period, (3) they had claims for cancer or hospice stay during study period. This study was approved by the University of Maryland, Baltimore (UMB) Institutional Review Board. A waiver of consent has been approved per 45 CFR 46.116(d).

\section{Outcome Measures}

Changes in the opioid utilization before and after TNFi initiation were compared using the following measures:

1. Proportion of patients receiving $\geq 1$ opioid prescription. 
Table 1 Baseline patient characteristics

\begin{tabular}{|c|c|}
\hline Variable & All $(n=2330)$ \\
\hline Age, mean (SD) & $51.7(11.0)$ \\
\hline \multicolumn{2}{|l|}{ Sex, $n(\%)$} \\
\hline Female & $1749(75.1)$ \\
\hline Male & $581(24.9)$ \\
\hline \multicolumn{2}{|l|}{ Region, $n$ (\%) } \\
\hline Northeast & $527(22.6)$ \\
\hline Midwest & $668(28.7)$ \\
\hline South & $877(37.6)$ \\
\hline West & $258(11.1)$ \\
\hline \multicolumn{2}{|l|}{ Insurance type, $n(\%)$} \\
\hline Commercial & $1294(55.5)$ \\
\hline Self-insured & $956(41.0)$ \\
\hline Other $^{a}$ & $80(3.4)$ \\
\hline \multicolumn{2}{|l|}{ Plan type, $n(\%)$} \\
\hline $\mathrm{HMO}$ & $345(14.8)$ \\
\hline PPO & $1704(73.2)$ \\
\hline Other $^{b}$ & $279(3.4)$ \\
\hline \multicolumn{2}{|l|}{ Comorbidities, $n$ (\%) } \\
\hline COPD & $376(16.1)$ \\
\hline Diabetes & $309(13.3)$ \\
\hline Hypertension & $892(38.3)$ \\
\hline Hypercholesterolemia & $793(34.0)$ \\
\hline Pain $^{c}$ & $997(42.8)$ \\
\hline Fracture & $92(3.9)$ \\
\hline Infection & $232(10.0)$ \\
\hline Depression & $297(12.7)$ \\
\hline Anxiety & $205(8.8)$ \\
\hline Cardiovascular events ${ }^{\mathrm{d}}$ & $132(5.7)$ \\
\hline
\end{tabular}

HMO Health Maintenance Organization, PPO Preferred Provider Organization, COPD chronic obstructive pulmonary disease

a Medicaid, Medicare advantage, unknown/missing

b Consumer directed health care, fee-for-service, point of service, unknown/missing

${ }^{c}$ Non-arthritis pain

d Cardiovascular events include myocardial infarction, stroke, angina pectoris, and congestive heart failure
2. Proportion of patients receiving $\geq 50 \mathrm{mg}$ median daily morphine equivalent dose (MED).

MED was calculated by multiplying opioid strength, quantity, conversion ratio, and dividing the sum by total days supplied.

\section{Statistical Analysis}

Statistical analyses were conducted using SAS version 9.4 (SAS Institute, Cary, NC, USA). The change in proportion of opioid users from preindex to post-index was assessed using McNemar's Chi-square test to account for correlation due to paired measurements.

\section{RESULTS}

Among 2330 patients who met eligibility criteria, mean age was 51.7 years old and $75 \%$ were female (Table 1). A majority of patients had commercial insurance and preferred provider organization as their plan. Among included individuals, $38.8 \%$ used opioids throughout the study period, $15.2 \%$ discontinued the use in post-index, $12.2 \%$ newly initiated during postindex, and $33.8 \%$ had no use throughout the study period (Table 2). Among 1259 patients who had opioid use during the pre-index period, 28.1\% discontinued. Among 1071 patients who had no opioid use during the pre-index period, $26.5 \%$ initiated opioids in the post-index period following TNFi initiation. From preindex to post-index, the proportion of patients receiving any opioid as well as those who received $\geq 50 \mathrm{mg}$ median daily MED decreased. Any opioid utilization decreased from $54.0 \%$ in pre-index to $51.0 \%$ in post-index and $50 \mathrm{mg}$ or

Table 2 Opioid pattern of use

\begin{tabular}{llll}
\hline $\boldsymbol{n}(\%)$ & \multicolumn{4}{l}{ Post-index use } \\
\hline Pre-index use & Yes & No & Total \\
Yes & $905(38.8)$ & $354(15.2)$ & $1259(54.0)$ \\
No & $284(12.2)$ & $787(33.8)$ & $1071(46.0)$ \\
Total & $1189(51.0)$ & $1141(49.0)$ & $2330(100.0)$ \\
\hline
\end{tabular}


Table 3 Change in opioid use

\begin{tabular}{lccc}
\hline Measure & Pre-index & Post-index & $\boldsymbol{p}$ value \\
\hline Proportion of patients receiving any opioid, $n(\%)$ & $1259(54.0)$ & $1189(51.0)$ & 0.006 \\
Proportion of patients receiving $\geq 50 \mathrm{mg}$ daily MED, $n(\%)$ & $293(12.6)$ & $246(10.6)$ & 0.005 \\
\hline
\end{tabular}

greater daily MED of opioid utilization decreased from 12.6 to $10.6 \%$ (Table 3).

\section{DISCUSSION}

This study found a modest $3.0 \%$ decrease in overall proportion of patients using opioid after TNFi initiation. Our findings are consistent with previous research, which have found a small overall decrease in the proportion of patients using opioids after DMARD initiation [15, 16]. However, the decrease may be deemed significant when looking at the patients who were using opioid before TNFi initiation. Further, we found there was a considerable proportion of patients with no opioid use in the pre-index period but initiated them after TNFi initiation. This new opioid initiation post-TNFi may reflect an unmet need in pain management. Pain symptoms in RA could be due to different mechanisms including inflammation, structural joint damage, or central sensitization and residual pain even after RA treatment is possible [17]. This study provides a more comprehensive examination of opioid use pre- and post TNFi initiation, including overall opioid use, proportion of patients with new opioid use, proportion of those with opioid discontinued, and proportion of patients with high daily MED of opioids. Study findings add to existing knowledge about opioid use in commercially insured RA population, which may behave differently than those populations in previous studies such as Medicare beneficiaries.

Limitations of the study include the lack of data on indications for which opioids were prescribed and the uncertainty of actual use of opioids by patients. Since many patients also had non-arthritis pain, it is possible that they were taking opioids for conditions other than RA. In addition, findings of this study are only generalizable to the commercially insured population in the United States. Disease severity of RA including disease activity or remission is an important factor that we were not able to capture in this study due to unavailability of such clinical information in the claims database.

\section{CONCLUSIONS}

Opioid use among patients with RA is prevalent. Lower opioid use following TNFi initiation suggests potential benefits of TNFi in pain control and reduction in opioid use for patients with RA. Newly initiated opioid users after TNFi initiation may reflect an unmet need in pain management due to the complex mechanism of pain in RA or the complex comorbidity profile in these patients.

\section{ACKNOWLEDGEMENTS}

The statements, findings, conclusions, views, and opinions contained and expressed in this manuscript are based in part on data obtained under license from IQVIA ${ }^{\mathrm{TM}}$. Source: IQVIA ${ }^{\mathrm{TM}}$ Health Plan Claims Data, January 2007-December 2015, IQVIA ${ }^{\mathrm{TM}}$. All Rights Reserved. The statements, findings, conclusions, views, and opinions contained and expressed herein are not necessarily those of IQVIA ${ }^{\mathrm{TM}}$ or any of its affiliated or subsidiary entities.

Funding. No funding or sponsorship was received for this study or the publication of this article.

Authorship. All named authors meet the International Committee of Medical Journal Editors (ICMJE) criteria for authorship for this article, take responsibility for the integrity of 
the work as a whole, and have given their approval for this version to be published.

Disclosures. Julia F. Slejko has received funding for research unrelated to the study from Novartis Pharmaceuticals Corporation, Takeda pharmaceuticals, PhRMA and PhRMA Foundation as well as teaching honorarium from Pfizer, Inc., unrelated to study. Siyeon Park, Tham T. Le, Julia F. Slejko, Ester Villalonga-Olives and Eberechukwu Onukwugha have nothing to disclose.

Compliance with Ethics Guidelines. This study was approved by the University of Maryland, Baltimore (UMB) Institutional Review Board. A waiver of consent has been approved per 45 CFR 46.116(d).

Data Availability. The IQVIA ${ }^{\mathrm{TM}}$ Health Plan Claims Data used for the analyses in this paper are available from IQVIA ${ }^{\mathrm{TM}}$. The license agreement to access these data does not give the authors permission to share this database.

Open Access. This article is distributed under the terms of the Creative Commons Attribution-NonCommercial 4.0 International License (http://creativecommons.org/licenses/ by-nc/4.0/), which permits any noncommercial use, distribution, and reproduction in any medium, provided you give appropriate credit to the original author(s) and the source, provide a link to the Creative Commons license, and indicate if changes were made.

\section{REFERENCES}

1. Cutolo M, Kitas GD, van Riel PLCM. Burden of disease in treated rheumatoid arthritis patients: going beyond the joint. Semin Arthritis Rheum. 2014;43(4):479-88.

2. Hunter TM, Boytsov NN, Zhang X, Schroeder K, Michaud K, Araujo AB. Prevalence of rheumatoid arthritis in the United States adult population in healthcare claims databases, 2004-2014. Rheumatol Int. 2017;37(9):1551-7.

3. Englbrecht M, Kruckow M, Araujo E, Rech J, Schett $\mathrm{G}$. The interaction of physical function and emotional well-being in rheumatoid arthritiswhat is the impact on disease activity and coping? Semin Arthritis Rheum. 2013;42(5):482-91.

4. Singh JA, Saag KG, Bridges SL, et al. 2015 American College of Rheumatology Guideline for the Treatment of Rheumatoid Arthritis. Arthritis Care Res (Hoboken). 2016;68(1):1-25.

5. Gibofsky A. Current therapeutic agents and treatment paradigms for the management of rheumatoid arthritis. Am J Manag Care. 2014;20(7 Suppl):S136-44.

6. Heiberg T, Kvien TK. Preferences for improved health examined in 1,024 patients with rheumatoid arthritis: pain has highest priority. Arthritis Rheum. 2002;47(4):391-7.

7. Sokka T. Assessment of pain in rheumatic diseases. Clin Exp Rheumatol. 2005;23(5 Suppl 39):S77-84.

8. Taylor PC, Moore A, Vasilescu R, Alvir J, Tarallo M. A structured literature review of the burden of illness and unmet needs in patients with rheumatoid arthritis: a current perspective. Rheumatol Int. 2016;36(5):685-95.

9. Grijalva CG, Chung CP, Stein CM, Mitchel EF Jr, Griffin MR. Changing patterns of medication use in patients with rheumatoid arthritis in a Medicaid population. Rheumatol. 2008;47(7):1061-4.

10. Zamora-Legoff JA, Achenbach SJ, Crowson CS, Krause ML, Davis JM, Matteson EL. Opioid use in patients with rheumatoid arthritis 2005-2014: a population-based comparative study. Clin Rheumatol. 2016;35(5):1137-44.

11. Whittle SL, Richards BL, Husni E, Buchbinder R. Opioid therapy for treating rheumatoid arthritis pain. Cochrane Database Syst Rev. 2011;11:3-5.

12. Dowell D, Haegerich TM, Chou R. CDC guideline for prescribing opioids for chronic pain-United States, 2016. JAMA. 2016;315(15):1624-45.

13. Wiese AD, Griffin MR, Stein CM, Mitchel EF, Grijalva CG. Opioid analgesics and the risk of serious infections among patients with rheumatoid arthritis: a self-controlled case series study. Arthritis Rheum. 2015;68(2):323-31.

14. Acurcio FA, Moura CS, Bernatsky S, Bessette L, Rahme E. Opioid use and risk of nonvertebral fractures in adults with rheumatoid arthritis: a nested case-control study using administrative databases. Arthritis Rheumatol. 2016;68(1):83-91.

15. Kawai VK, Grijalva CG, Arbogast PG, et al. Changes in cotherapies after initiation of disease-modifying antirheumatic drug therapy in patients with 
rheumatoid arthritis. Arthritis Care Res (Hoboken). 2011;63(10):1415-24.

16. Accortt NA, Schenfeld J, Chang E, Papoyan E, Broder MS. Changes in healthcare utilization after etanercept initiation in patients with rheumatoid arthritis: a retrospective claims analysis. Adv Ther. 2017;34(9):1-11.

17. Whittle SL, Richards BL, Buchbinder R. Opioid analgesics for rheumatoid arthritis pain. JAMA. 2013;309(5):485-6. 